\title{
Manufacturing Specialization in the Southeast: Rural Necessity, Rural Possibility, or Rural Vestige?
}

\section{Timothy R. Wojan and Steven Brent Lackey*}

\begin{abstract}
This paper examines the validity of three alternative rationales for industrial specialization in rural areas. Manufacturing specialization can be explained by 1) the greater efficiency of very large plants; 2) the "localization" advantages identified with a number of firms in the same industry locating near each other; or 3) a strategy to gain bargaining power in isolated rural labor markets by a dominant employer. Eleven logistic regressions are estimated for each of the specializations identified using cluster analysis. At least one of the explanations is supported in each of the specialization regressions, but different explanations charaterize the various industries.
\end{abstract}

\section{INTRODUCTION}

The objective of this analysis is to increase understanding of the possible reasons for manufacturing specialization in rural areas. Framing rational policy responses to the potential economic opportunities or crises that may emerge from dependency on a single manufacturing industry requires such understanding. Three alternative rationales for manufacturing specialization are investigated in this paper. Manufacturing specialization in rural areas is thought to be explained by 1 ) the exploitation of scale economies by very large plants; 2 ) the "localization" advantages identified with a number of firms in the same industry locating near each other; or 3) a strategy to gain bargaining power in isolated rural labor markets by a dominant employer in the county. To test these rationales, cluster analysis is used to identify counties that are specialized in an industry at the 2-digit SIC level. The results are then used in an econometric exercise to identify the characteristics associated with manufacturing specialization.

As the research interest in industrial specialization has increased over the past decade, so too have the number of ways to define the phenomenon. Two critical issues in this respect are the level of spatial aggregation and the level of industry aggregation used in the analysis. County-level analysis has the advantage of mapping political boundaries so that the results are directly applicable to local policy makers. The disadvantage is that economic relationships-defined by commuting patterns or local supply chains-typically permeate these boundaries. On balance, we find the appeal to local policy in the former persuasive, especially given the importance of "locality" in much of the industrial district literature (see Pyke and Sengenberger 1992). The most appropriate level of industry aggregation

*Economist, Economic Research Service, USDA; and Research Specialist, TVA Rural Studies, University of Kentucky. The views expressed herein are the authors' and do not necessarily represent the views of their respective institutions. The authors wish to thank David Freshwater, David McGranahan, and two anonymous reviewers for comments that improved earlier drafts. However, any errors are the sole responsibility of the authors. 
is also contentious, as it should emphasize the similarities in input use, response to macroeconomic conditions, and the nature of technical problems while minimizing differences across detail industries. In the present case, the 2-digit level of aggregation in the SIC code is dictated by our use of publicly available data. While this aggregation scheme may not be optimal, we feel that it provides a reasonable approximation to the aggregation criteria discussed above. In the analysis that follows, "manufacturing specialization" refers to a dominant share of county employment within a 2-digit SIC code.

This research is motivated by considerable uncertainty regarding the dangers or benefits of industrial specialization, which only recently became a contentious issue. The traditional view presumes that diversifying the sources of employment and income in a community provides stability to the local economy and that specialization in just one industry creates strong vulnerabilities to economic shocks. This belief in industrial diversification as a desirable policy goal derives support from the analogy of an investment portfolio in which the collection of industry is thought to determine the stability of a local economy (Brown and Pheasant 1987; Smith and Gibson 1988, Shaffer 1989). However, as the parallels between international and interregional trade became more focused, concerns arose that significant gains from interregional trade might be forsaken in pursuit of industrial diversification (Gilchrist and St. Louis 1991). Competitive advantages from increased specialization have also been suggested from recent work on endogenous growth (Romer 1986) and industrial clusters (Henry and Drabenstott 1996). Rural industrial development research should examine all plausible explanations for industry specialization to better assess the potential costs or benefits of the various patterns of development.

\section{OPERATIONALIZING RATIONALES FOR INDUSTRIAL SPECIALIZATION}

Two important steps secure the foundation of this study. First, support for each of the alternative rationales is generated from a review of the literature. Second, the development of proxies for the three rationales is discussed along with an assessment of their validity.

\section{Internal Economies of Scale}

The literature generally supports the conjecture that minimum efficient scale of production may explain industrial specialization in the rural case. According to Krugman (1991), it is the interaction of scale economies in production and marketing with transportation economies and geographic concentration of raw materials that determines tendencies toward specialization in a fewer number of sites or dispersal across the economic landscape. The new economic geography posits that a decrease in transportation costs and an increase in internal scale economies will result in production concentrating in fewer locations. While the decline in transportation costs in modern times is seemingly incontrovertible (Kilkenny 1998), the direction of internal scale economies is more contentious. 
Trends in the magnitude and direction of scale economies have varied across manufacturing industries over time (Milgrom and Roberts 1990). This provides a source of empirical leverage later in the analysis when we compare the relative importance of minimum efficient scale of production explaining specialization across industries.

The association of the product life cycle hypothesis of industrial development with rural industrialization supports the minimum efficient scale of production rationale. Within this framework, emergent industries will be characterized by a large number of small, diverse market niches. Mature industries will be characterized by larger markets of more standardized products with standardized production processes. Firms are thus more apt to make large investments in purposebuilt machinery to replace the higher variable cost combination of general-purpose machinery and more highly skilled workers. Since cost becomes an increasingly important mediator of exchange, these industries will tend to seek out the lower factor costs available in rural areas.

Support for the minimum efficient scale of production argument is also found in the industrial organization literature. Both George (1972) and Eckard (1994) present evidence that economies of scale at the plant level are more important than economies of scale at the firm level. Put another way, technical economies of scale in production appear to be real and are not merely artifacts of organizational economies of scale in marketing and distribution. This result has strong implications for the minimum efficient scale of production argument, as the analysis only has to consider the relative size of establishments and not their subsidiary status.

The difficulty in examining this rationale empirically is in identifying a proxy that does not lead merely to a tautological interpretation. Average establishment size for the industry in the county would do little more than confirm that the presence of significantly larger plants increases the probability of being specialized without providing any information on the presence of significant scale economies.

Given the 2-digit SIC definition of specialization, a valid proxy must incorporate two sources of information to determine when large plant size corresponds to scale economies. First, within each detail industry at the 4-digit level there is typically significant variation in plant size. Data in the Census of Manufacturers provides information on the average plant size of the fifty largest U.S. companies (by sales) in each 4-digit SIC, suggesting the size of core or primary plants within a detail industry. ${ }^{1}$ Eckard (1994) provides a rationale for associating this metric with minimum efficient scale of production-if internal economies of scale do exist they are most likely to be exploited by the top firms. Second, within a 2-digit category, there may be significant variation in average plant size across the detailed 4-digit SIC industries. For example, an automobile parts plant (SIC 3714) employing 500 workers would be large relative to other auto parts plants but a passenger car body plant (SIC 3711) of this size would be relatively small. A valid

\footnotetext{
${ }^{1}$ Unfortunately, the last time these data were compiled was in the 1977 Census of Manufacturers.
} 
proxy should indicate when local plants within their respective 4-digit classifications are operating at or near the size of core plants.

To construct this proxy, the establishment size distribution for each county down to the 4-digit level provided in County Business Patterns is coupled with Census of Manufacturers information on the average plant size of the 50 largest U.S. companies (by sales) in each 4-digit SIC code. The matrix product of these two vectors divided by the total number of establishments in that industry operating in the county provides an estimate of average plant size if local firms were operating at a scale similar to establishments in the top 50 firms in the country. The actual average establishment size for the county is divided by the constructed value discussed above to derive a measure of the size of local plants relative to this minimum efficient scale estimate. In notation, the two steps can be summarized by the following expression:

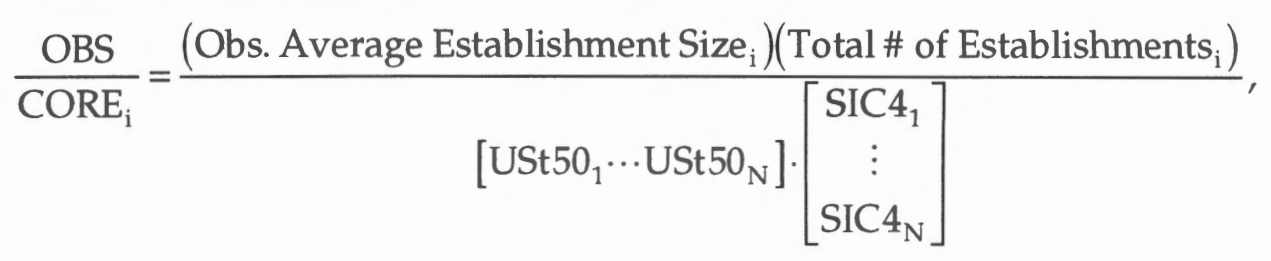

where:

USt $50_{k}=$ average establishment size of the 50 largest firms in the 4-digit industry $\mathrm{k}$ included in the 2-digit industry $\mathrm{i}$;

$\mathrm{SIC}_{\mathrm{k}}=$ the number of establishments in the county in the 4-digit industry $\mathrm{k}$ included in the 2-digit industry $\mathrm{i}$.

If the OBS/CORE proxy is close to one, it is believed that the establishments located in the area are operating near minimum efficient scale, and a positive sign will corroborate this hypothesis.

\section{Localization}

Recent work on rural industrial development suggests an alternative explanation for industry specialization emphasizing the importance of external economies of scale (Henry and Drabenstott 1996; Barkley and Henry 1997; Henry, Barkley, and Zhang 1997). The empirical portion of this work confirms that larger concentrations of industry employment in a region are associated with faster rates of employment growth (Henry and Drabenstott 1996; Henry, Barkley, and Zhang 1997). This result is used to suggest the reasonableness of competitive advantages flowing from the localization of economic activity. As identified by Marshall (1920), localization provides the following benefits: 1) a pooled market for workers with specialized skills; 2) the provision of nontraded inputs to an industry with greater variety and lower cost; and 3) information flows that create technological spillovers.

Since there is no inclusion of variables that address the concentration of industry employment across firms in these earlier analyses it is not possible to dis- 
cern the effects attributable to external versus internal economies of scale. A large industry presence could be the result of one or a few larger firms or a collection of numerous smaller firms. By explicitly considering the concentration of industry employment across firms, this analysis can empirically assess the veracity of claims regarding external economies of scale due to localization effects.

Given the discussion above, we propose an axiomatic justification for the measure used to test the localization hypothesis. The measure should be increasing in the number of firms in a county-the assumption is that the probability of technological spillovers, sourcing inputs locally, or deriving labor pooling advantages will increase as the number of establishments in an industry increases. However, the raw number of firms by itself is insufficient as it ignores the size dependency of some of these benefits. For example, establishments of similar size are more likely to be operating at similar levels of technological sophistication, increasing the value of potential spillovers. Similarly, employment opportunities will be the most substitutable across similar size establishments. Thus, the measure should also be increasing in the dispersion of employment across several firms. ${ }^{2}$ A composite measure that satisfies these requirements can be expressed as follows (see the Appendix for a fuller discussion of the proxy):

$$
\text { LOC }_{i}=\frac{\text { Number of Firms }_{i}}{\sum_{n \text { in }}\left(\frac{\text { Establishment Employment }_{n}}{\text { Industry Employment }}\right)_{i}^{2}} .
$$

LOC will equal one in the case of a single establishment in industry $i$ and increases as the number of establishments and the dispersion of employment across these plants increases. The localization hypothesis will be corroborated by a positive coefficient estimate.

\section{Monopsony}

The "company town" construct is powerful in suggesting the strategic motivation for locating large plants in small places of relative isolation. While evidence of the company town phenomenon is largely anecdotal-and this anecdotal evidence is inconclusive (e.g., Boal 1995)-our epistemological motivation is one of confirmation requiring that we consider all plausible alternatives (for theoretical motivation see Yeh, Mai, and Shieh 1996 and Jones 1988).

\footnotetext{
2The validity of this assumption can be challenged, especially given the variety of "hybrid" forms of industrial districts being identified in the literature. However, if the measure is attempting to identify possible Marshallian districts in their canonical form, then this axiomatic assumption is justified. For example, in addressing firm size in the Third Italy, Becattini (1990) states that "[c]oalitions and agreements of various kinds and importance between firms in the district also occur, but whenever the weight of those which take a financial form increases too much, or the growth of some firm sends it 'out of scale,' as it were, we are already out of the canonical form of the Marshallian district" (p. 41). In the same volume, Piore (1990) identifies the importance of a "community of equals" in understanding the coexistence of competition and collaboration that is a defining characteristic of the Marshallian industrial district (p. 67). However, the measure constructed in this analysis is still sensitive to network relations that may form in a dominant firm hybrid of the industrial district, discussed in the Appendix. See also Schmitz (1992).
} 
To test empirically this explanation we again find the Herfindahl Concentration Index productive-though this time in its canonical form. We examine concentration in the manufacturing sector as a whole. It is calculated as follows:

$$
\text { MON }=\sum_{n}\left(\frac{\text { Establishment Employment }_{n}}{\text { Total Manufacturing Employment }}\right)^{2} \text {. }
$$

If a county is truly a "company town" and only has one manufacturing firm, then the Herfindahl Index (MON) would have a value of one. Thus, we would expect a positive sign on the coefficient of the monopsony power variable if this were a valid explanation of industry specialization. Export base theory serves as justification for only including manufacturing employment in measuring monopsony power. Manufacturing industries are considered "basic," or exporting, activities. For nonbasic businesses, demand is dependent on the local level of income. In a low-wage economy, most nonbasic businesses are not likely to provide productivity and wage levels higher than the basic sector for equivalent types of work. Thus, these employment opportunities are unlikely to provide significant competition for labor in the basic sector.

\section{THE DATA}

Studies of the industrial structure of rural regions of the U.S. have been hindered by nondisclosure of detailed data. The problem is addressed here using a simple algorithm that uses disclosed employment size ranges in County Business Patterns (CBP) to arrive at consistent employment estimates at the 2-digit SIC level (Kreahling, Smith, and Frumento 1996). ${ }^{3}$

These employment estimates are then used in a disjoint cluster analysis to identify industrial structures that may demonstrate single-industry specialization. ${ }^{4}$ Cluster analysis is a statistical technique that classifies objects (counties) into groups based on the similarity of the object's collection of attributes. In this study, the share of total private county employment in export base industries comprises the collection of county attributes, i.e., all 2-digit manufacturing industries, mining, and business services. For example, counties that have a high percentage of total employment in the Textiles industry would likely be grouped together. It is important to note that the clusters are not constructed according to a specific threshold, rather, it is the composition of all industry sectors in total that groups the various counties.

Industry employment shares are defined as the proportion of total private employment rather than total employment. The policy goal of diversification seeks to lessen the variability in output caused by a change in market demand, which argues against including a largely exogenous source of government employment. Export base theory serves as the justification for limiting the analy-

${ }^{3}$ Comparing results from the estimation procedure with data provided in the ES-202 series available for an individual state is encouraging. Major discrepancies arise only when county employment is reported by an administrative unit elsewhere in the state for the ES-202 series. This suggests a considerable advantage to using the CBP estimates in analyses utilizing employment levels. However, the estimates are not appropriate for examining changes in employment over time.

4 PROC FASTCLUS, available in the SAS Statistical Package, is used in the analysis. 
sis to manufacturing, mining, and exportable service-producing industries (Shaffer 1989). The computation of locational Gini coefficients confirms that "locational clustering" is most pronounced for manufacturing and selected service sectors (Barkley and Henry 1997).

The analysis includes all counties in Alabama, Georgia, Kentucky, Mississippi, North Carolina, South Carolina, Tennessee, and Virginia. Reducing the sources of bias motivates the inclusion of metropolitan counties. The exclusion of metropolitan counties would be arbitrary, especially in the context of the South where many smaller metropolitan places maintain strong specialization in manufacturing. Since there are believed to be metro counties in the South specialized in a specific manufacturing industry, truncating the data set would change the shape of the probability distribution, resulting in biased parameter estimates (Griffiths, Hill, and Judge 1993).

The resulting cluster structure contains 15 county types, 13 of which can be described as industry specializations. Two of these specializations are nonmanufacturing industries: one in Mining and one in Business Services. The manufacturing specializations make up 11 of the clusters, which correspond to the following industries: Food and Kindred Products, Textiles, Apparel, Lumber, Furniture, Paper, Chemicals, Primary Metals, Fabricated Metals, Electrical Equipment, and Transportation Equipment.

The inclusion of metropolitan counties also allows differentiation of the industry specialization clusters with respect to their relative rurality. For each industry specialization cluster, Table 1 shows the percentage of the specialized counties that are considered either metropolitan or rural, and it illustrates the percentage of rural counties that are adjacent to metropolitan counties. Table 1 also shows the percentage of rural counties that have a small, medium, or large urban population. Not surprisingly, those industries with the strongest association to natural resource bases have a tendency to concentrate in rural areas. These include the Mining, Food and Kindred Products, Lumber, and Paper industries. Other specializations located mainly in rural areas include Apparel and Fabricated Metal. Those industries most likely to support specializations in metropolitan areas include Primary Metals, Chemicals, Furniture, and exportable servicesproducing industries. The statistics in Table 1 also lend support to our contention that industry specialization is predominantly a rural phenomenon. For all manufacturing specializations, 83 percent of these counties are rural. However, a significant minority of metropolitan counties is specialized in one industry, justifying the inclusion of all counties in the analysis.

\section{THE EXTENT OF SINGLE-INDUSTRY SPECIALIZATION IN THE SOUTHEAST}

Before proceeding to the econometric exercise, it is productive to examine the cluster structure in more detail to affirm that the algorithm has successfully identified "industry specializations." Comparison with the widely used USDA 


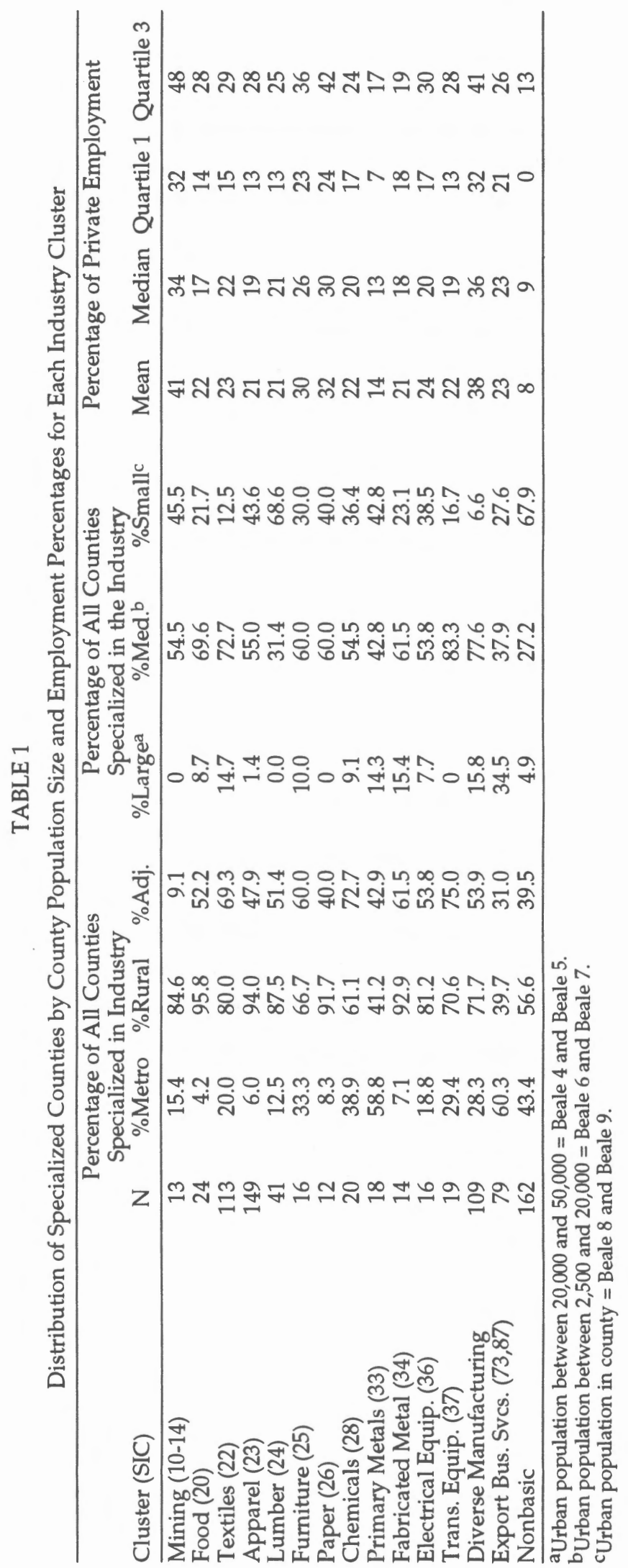


typology of rural county dependency provides a reference point to assess whether the employment shares of the dominant industry in each cluster are all that large. Unfortunately, the USDA typology is constructed using the share of income from economic sectors, obviating a direct comparison. Manufacturing-dependent counties are classified as those deriving at least 30 percent of total income from the sector (Cook and Mizer 1994). However, this threshold corresponds roughly with 30 percent of total private employment in terms of employment share in manufacturing as observed in the Southeast. Using this employment share cutoff as a proxy for the income share cutoff used in the USDA typology, 83 of the 453 (18.32 percent) specialized counties identified in this analysis would qualify as manufacturing dependent on the basis of employment in just the dominant 2-digit industry. Put another way, of the 255 manufacturing-dependent counties in the region, as classified by USDA, nearly one-third of these (32.54 percent) could be classified as single-industry dependent at the 2-digit level.

Descriptive statistics concerning the specialized industry's share of county employment for each of the clusters are also provided in Table 1. The mean, median, and quartiles for the employment shares of the dominant industries are given and, with the exception of Primary Metals, the mean employment share is always greater than 20 percent for each of the manufacturing specializations.

\section{THE MODEL}

The objective of the econometric exercise is to identify which of the rationales, if any, are associated with the identification of a county as specialized. The binary indicator of a county being specialized or not being specialized in a particular industry is modeled using a logistic regression estimator. ${ }^{5}$ The logit model estimates the probability of an event based on explanatory factors in such a way that the probability remains in the interval $[0,1]$. Maximum likelihood estimation (MLE) is used and provides consistent estimates of the parameter coefficients.

The probability of a county being specialized in an industry, as a function of the alternative rationales discussed earlier, is modeled as:

$$
P_{i}=\frac{1}{\left(1+e^{-X^{\prime} \beta}\right)}
$$

where:

$$
-X^{\prime} \beta=\beta_{0}+\beta_{1} \frac{\mathrm{OBS}}{\mathrm{CORE}_{\mathrm{i}}}+\beta_{2} \mathrm{LOC}_{\mathrm{i}}+\beta_{3} \mathrm{MON}_{\mathrm{i}}+\beta_{4} \mathrm{POP}_{\mathrm{i}}
$$

$P_{i}=$ the probability of county $i$ being specialized in the industry being tested; OBS $/ C O R E_{i}=$ the ratio of observed plant size to proxy for minimum efficient scale of production in county $i$ for the tested industry;

$\mathrm{LOC}_{\mathrm{i}}=$ localization economies in county $\mathrm{i}$ for this industry;

$\mathrm{MON}_{\mathrm{i}}=$ monopsonistic power in county $\mathrm{i}$;

$\mathrm{POP}_{\mathrm{i}}=$ population of county $\mathrm{i}$.

${ }^{5}$ PROC LOGISTIC, available in the SAS Statistical Package, is used in the analysis. 
The model is estimated for each of the 11 manufacturing specializations identified by the cluster analysis. The hypothesis tests of interest are whether or not the individual parameters associated with the various proxies of the rationales for rural specialization are powerful in explaining the probability that a county is specialized in an industry. The critical significance level is set at 0.05 for a two-tailed test for the localization (LOC), monopsony (MON), and population (POP) variables. In the interest of greater statistical power-and the fact that a negative coefficient estimate is implausible-we utilize a one-tailed test for the ratio of observed size to minimum efficient scale (OBS/CORE) estimate at the 0.05 level (see Goldberger 1991, pp. 237-238).

The explanatory variables in the model are proxies for plant size relative to minimum efficient scale of production (OBS/CORE), localization economies (LOC), and monopsony power (MON). Since the descriptive statistics suggest that manufacturing specialization is more common in rural counties (see Table 1), excluding a measure of settlement size will bias the estimates of the three specialization variables. For example, MON will tend to be larger in less populous counties. By excluding the settlement size variable, any association between specialization and MON will be larger, but part of this effect should be attributed to the excluded variable. We include county population (POP) to control for these potentially confounding effects. In addition, the variable allows examination of the maintained hypothesis that specialization is explained by the combination of one of the three rationales with small settlement size. Since the influence on the probability of specialization of any one of the variables is dependent on the value of the other variables in the logit specification, examining the marginal effects at different values of county population can directly address this hypothesis.

\section{RESULTS}

In general, the results of the econometric exercise (summarized in Table 2) are promising. For each industry, the system statistics (log-likelihood test, concordant probabilities, and the pseudo $\mathrm{R}^{2}$ ) suggest that the model as a whole is powerful in identifying various characteristics associated with specialization. As shown in Table 2, the log-likelihood ratio test statistic is highly significant for each industry, which provides evidence that the model is identifying factors associated with the probability of a county being specialized. At least one of the variables is significant in each equation (Table 2), but it is notable that the collection of significant variables differs by regression. ${ }^{6}$ The implications are that industries differ in important respects, which devalues aggregate analysis of "the manufacturing

\footnotetext{
${ }^{6}$ The results of the post hoc power analysis are important at this juncture. Generally, we find that power falls precipitously as the percentage of countries specialized falls below 5 percent. However, the power of the test is also determined by the sample size and the correlation of the variable of interest with the other independent variables. While a low power test will not affect the inferences derived from a positive result, it does require one to suspend judgement on the implications of all estimates that are not statistically significant. That is, derivation of an insignificant coefficient is not interesting, as the test has a low probability of rejecting the null even if it is false in the population. Setting a criterion of Power $=0.8$ (i.e., the probability of Type II error $=b=1-$ Power $=0.2$ ) as an acceptable threshold, 5 of the 11 equations have low power: Furniture, Paper, Fabricated Metals, Electrical Machinery, and Transportation Equipment. In these equations, estimates that are not statistically significant provide no usable information on the likely effect of the variable in the population.
} 
sector." These results imply industry specificity will be important in framing appropriate policy responses to industrial specialization.

However, the statistical success of the exercise should make us more sensitive to the economic information actually conveyed by the analysis. For example, the plant size to minimum efficient scale (OBS/CORE) variable is significant in each equation using a one-tailed test (Table 2). The prudent question regarding this result is whether the OBS/CORE variable is capturing information that is distinct from the average observed establishment size variable used to construct the proxy. A strong correlation between OBS/CORE and observed firm size $(r>0.80)$ seriously devalues the economic interpretation of the OBS/CORE estimate for the Apparel, Lumber, Furniture, Electrical Equipment, and Fabricated Metals industries. In these cases, relative establishment size is largely indistinguishable from the relative size of the OBS/CORE proxy, making inferences tautological.

In the remaining six regressions there are two distinct phenomena observed. For each of the 11 manufacturing specializations, Table 3 provides the estimated average firm size at the 2-digit level given the county's composition of firms at the 4-digit level for all counties with industry employment and specialized counties. Estimated average firm size is computed as:

$$
\text { EAFS }_{\mathrm{i}}=\frac{\text { USave } \left._{1} \cdots \text { USave }_{\mathrm{N}}\right] \cdot\left[\begin{array}{c}
\mathrm{SIC}_{4} \\
\vdots \\
\mathrm{SIC}_{4}
\end{array}\right]}{\text { Total Number of Establishments }}{ }_{\mathrm{i}},
$$

where:

$\mathrm{EAFS}_{\mathrm{i}}=$ estimated average firm size for the county in the 2-digit industry $\mathrm{i}$; USave $_{k}=$ average establishment size of the firms in the 4-digit industry $k$ included in the 2-digit industry $i$;

$\mathrm{SIC}_{\mathrm{k}}=$ the number of establishments in the county in the 4-digit industry $\mathrm{k}$ included in the 2-digit industry $\mathrm{i}$.

Table 3 also gives the estimated average firm size at the 2-digit level if the establishments in the county were among the top 50 in the country. For the Paper, Chemicals, Transportation Equipment, and Primary Metals industries there are noticeable differences in the estimated average establishment size between specialized counties and all counties with industry employment. This suggests that specialization may be partially explained by differences in the 4-digit industry mix. In these cases, it is difficult to untangle the minimum efficient scale effects from the industry mix effects.

However, Textiles and Food provide strong evidence of the exploitation of scale economies consistent with the conceptual foundations of the proxy. With these industries, the estimated average establishment size is nearly identical for general and specialized counties and, as shown in Table 2, the OBS/CORE 





variable is highly significant for these two industries. Therefore, for the Food and Textiles industries, larger observed average plant size in specialized counties is arguably the result of core firms exploiting internal economies of scale.

\section{TABLE 3}

Estimated Average Firm Size Given the County's 4-Digit Compositiona (by Industry Cluster)

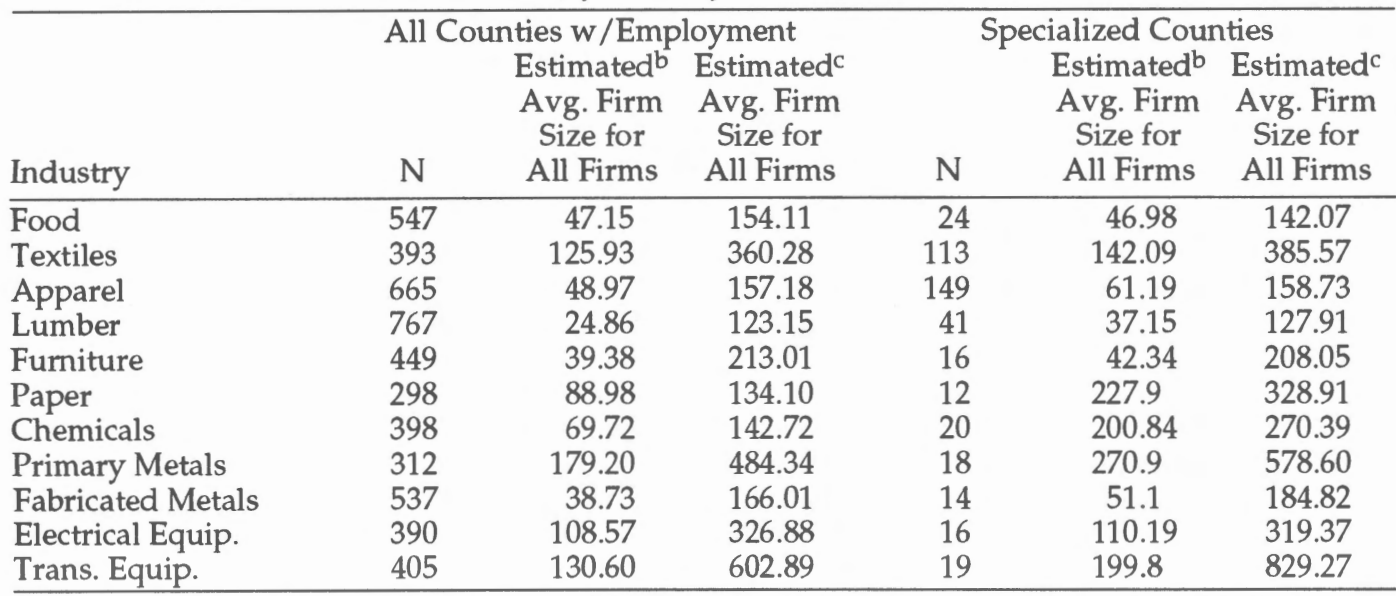

a Latest available establishment size data by 4-digit SIC Codes from 1977 Census of Manufacturers. Employment size represents average number of production workers per plant.

bstimated average firm size at the 2-digit level given the county's composition of firms within that industry at the 4-digit level.

${ }^{C}$ Estimated average firm size at the 2-digit level if the establishments are Top 50 firms in the country given the county's composition of firms within that industry at the 4-digit level and the average establishment size of the Top 50 firms at the 4-digit level.

The localization proxy (LOC) is positive and significant for the Food, Textiles, Apparel, Lumber, Furniture, Primary Metals, and Fabricated Metals industries (see Table 2). Again, a closer examination of the distribution of the localization variable is informative. For each of the manufacturing industry clusters, Table 4 compares the mean value of the localization proxy (LOC) for all counties with employment in that industry to the counties specialized in the industry. As shown in Table 4, the mean LOC values for specialized counties in the Food, Apparel, Primary Metals, and Transportation Equipment industries are relatively small and roughly equivalent to the mean LOC value for all counties with industry employment. This suggests that the strength of the association may result from correctly identifying nonspecialized counties.

A positive case of external economies being strongly associated with industry specialization is most evident for the Textiles and Furniture industries. As shown in Table 2, the coefficient estimates for the localization proxy are positive and significant for the Textiles and Furniture industries. For these two industries, the measure for the localization proxy for specialized counties is significantly greater than the measure for all counties with industry employment (Table 4), which provides evidence that the creation of localization economies plays a role in the counties specialized in Textiles and Furniture. The fact that both these industries have often been the focus of studies examining localization economies 
(Kristensen 1992; Piore and Sabel 1984; Sforzi 1990) reinforces the conclusion that this process may be operating in rural specializations.

TABLE 4

Values of the Localization Proxy (LOC)

for All Counties with Employment and Specialized Counties by Industry Cluster

\begin{tabular}{lcccc}
\hline & All Counties w/Employment & $\begin{array}{c}\text { Sean Value of } \\
\text { the Localization } \\
\text { Industry }\end{array}$ & $\mathrm{N}$ & $\begin{array}{c}\text { Specialized Counties } \\
\text { Mean Value of } \\
\text { the Localization } \\
\text { Proxy }\end{array}$ \\
\hline Food & 537 & 10.49 & $\mathrm{~N}$ & 9.48 \\
Textiles & 380 & 17.73 & 113 & 35.75 \\
Apparel & 653 & 11.07 & 149 & 7.18 \\
Lumber & 766 & 32.32 & 41 & 32.54 \\
Furniture & 31 & 12.35 & 16 & 96.06 \\
Paper & 294 & 6.58 & 12 & 1.74 \\
Chemicals & 393 & 10.72 & 20 & 3.79 \\
Primary Metals & 305 & 4.32 & 18 & 6.42 \\
Fabricated Metals & 521 & 19.13 & 14 & 8.04 \\
Electrical Equipment & 377 & 9.04 & 16 & 3.67 \\
Transportation Equipment & 397 & 5.84 & 19 & 3.67 \\
\hline
\end{tabular}

TABLE 5

Distribution of Firm Concentration (MON) Ratios for All Manufacturing Firms in Each Manufacturing Industry Cluster and Firm Concentration in Dominant Industry

\begin{tabular}{lcccc}
\hline & \multicolumn{2}{c}{$\begin{array}{c}\text { Firm Concentration (MON) Values } \\
\text { for All Manufacturing }\end{array}$} & $\begin{array}{c}\text { Firm Concentration } \\
\text { in Dominant } \\
\text { Industry }\end{array}$ \\
\hline Cluster & $\begin{array}{c}\text { Median } \\
(1)\end{array}$ & $\begin{array}{c}\text { Minimum } \\
(2)\end{array}$ & $\begin{array}{c}\text { Maximum } \\
(3)\end{array}$ & $\begin{array}{c}\text { Median } \\
(4)\end{array}$ \\
\hline Food & 0.3032 & 0.1815 & 0.5727 & 0.8424 \\
Textiles & 0.2572 & 0.1590 & 0.7360 & 0.4765 \\
Apparel & 0.3478 & 0.2030 & 0.8354 & 0.5990 \\
Lumber & 0.3848 & 0.2100 & 0.8633 & 0.4648 \\
Furniture & 0.2304 & 0.1244 & 0.6575 & 0.3441 \\
Paper & 0.4514 & 0.2639 & 0.7922 & 1.0000 \\
Chemicals & 0.3324 & 0.2107 & 0.5888 & 0.9500 \\
Primary Metals & 0.2779 & 0.1607 & 0.6948 & 0.6056 \\
Fabricated Metals & 0.3647 & 0.2127 & 0.6379 & 0.8322 \\
Electrical Equip. & 0.4222 & 0.2255 & 0.7551 & 1.0000 \\
Trans. Equip. & 0.3082 & 0.2078 & 0.6486 & 0.9477 \\
\hline
\end{tabular}

Descriptive statistics of the data combined with the regression results provide evidence that specialization in the Paper and Electrical Equipment industries may result from the pursuit of monopsony power. Examination of the concentration ratios of the entire manufacturing sector in the specialized counties for eaccluster (Table 5, column 1 ) indicates that none of the clusters demonstrate a highly concentrated industrial structure at the median. However, the Paper and Electrical Equipment clusters stand out as having the highest median values. Examining information on the concentration of firms within the dominant industry is productive (Table 5, column 4), as it is reasonable to assume that competition within a 2-digit manufacturing industry is more likely to threaten monopsony power rel- 
ative to competition across disparate manufacturing industries. ${ }^{7}$ Here we see that at least half of the specialized counties in Paper and Electrical Equipment have only one establishment in the dominant industry, demonstrated by a median value of one. We conclude that the possibility of monopsony power as an explanation of specialization is greatest in the Paper and Electrical Equipment industries.

The regression results corroborate this interpretation for counties specialized in Paper and Electrical Equipment (Table 2). In addition, the odds ratio for the monopsony power proxy is extremely high for both Paper and Electrical Equipment (Table 2). ${ }^{8}$ This suggests empirically that those counties with the highest concentration indexes are consistently specialized. Examining Table 1 reveals that a large majority of the specialized counties in both Paper and Electrical Equipment are rural counties with all of the counties specialized in Paper and 92.3 percent of the counties specialized in Electrical Equipment having urban populations less than 20,000 . The fact that many of these counties are most likely to contain small, more isolated labor forces reinforces the suggestion that the pursuit of monopsony power is a consistent explanation of specialization in the Paper and Electrical Equipment industries. ${ }^{9}$

Finally, a maintained assumption throughout the analysis has been that small population size contributes to the probability of being specialized in a single industry. The negative estimate on the Population variable in each of the equations supports this assumption. However, the interaction of population size with the three alternative explanations can be examined explicitly by computing the marginal effects of the OBS/CORE, LOC, and MON variables across different settlement size categories. Since the probability of being specialized is a nonlinear function of the $x^{\prime} s$ and $\beta$ 's, a critical decision is choosing the most appropriate level of the independent variables for evaluating these marginal effects. We use the mean level of the variables for each of the three settlement size categories we examine. These size categories include the smallest metropolitan category (Beale 3), the largest nonmetropolitan category for nonadjacent counties (Beale 5), and the smallest nonmetropolitan category for nonadjacent counties (Beale 9). The partial change in the probability, or marginal effect, of the kth variable is computed by

${ }^{7}$ For example, the shares of Apparel employment rank second to the dominant industry in 9 of the 10 other industry specializations. This may be explained as a gender segmentation of the labor force into male- and female-dominated sectors.

${ }^{8} \mathrm{~A}$ parameter estimate in a logistic regression represents the change in the log odds (logit) given a unit change in $x_{i}$ holding all other variables constant. Unfortunately, there is no intuitive interpretation of the log of the odds. The odds ratio is obtained by exponentiating the parameter estimate associated with the variable. This ratio has a natural interpretation indicating how the odds of an event change as you change $x$ from, say, 0 to 1 . For instance, an odds ratio of 2 means that the odds of an event when $x=1$ are twice the odds of an event when $x=0$. (See Long 1997, pp. 79-82.) In the current case, 999.0 is a limiting value on the computed odds ratio in the SAS software, suggesting that the probability of being a specialized county in Paper or Electrical Equipment is close to 0 when the MON variable is 0 , certeris paribus. But since the Herfindahl index cannot take on the value of 0 , this is difficult to interpret. However, the change in the odds can be calculated for any magnitude of a change in $\mathrm{x}$. The odds ratio-or more accurately the factor change-given a change in MON from 0.5 to 1 is still quite large for Paper (209.56) and Electrical Equipment (44.7).

${ }^{9}$ At least for the Paper industry, alternative explanations for the result may emerge from the importance of being close to large timber stocks or the strong disamenities associated with production, either of which would favor more sparsely populated locations. 
taking the partial derivative:

$$
\frac{\partial \operatorname{Pr}(y=1 \mid x)}{\partial x_{k}}=\lambda(x \beta) \beta_{k}=\left(\frac{e^{x \beta}}{\left[1+e^{x \beta}\right]^{2}}\right) \beta_{k},
$$

where: $\lambda(\cdot)$ represents the probability density function of the standard logistic distribution (see Long 1997, p. 72)

The computed marginal effects are presented in Table 6. As expected, the magnitude of the effects increases as average settlement size declines. However, it is the difference in magnitude that is most notable. The majority of marginal effects in the Beale 3 category are quite small, if not trivial. In comparison, the marginal effects in the Beale 9 category tend to be large, at least for variables with significant coefficient estimates in the various equations. In comparing the two nonmetro categories, we also find that larger population greatly reduces the probability that a county will be specialized owing to the effect of the three explanations tested.

\section{CONCLUSION}

We return to the original question: Is manufacturing specialization the result of rural necessity, rural possibility, or rural vestige? These three explanations correspond to the rationales of minimum efficient scale, localization, and monopsony power, respectively. Given the diversity of the industry structures, it is not surprising that no single rationale of industrial specialization is discovered in the analysis. Industrial specialization in the rural Southeast appears to be consonant with rural necessity, possibility, or vestige depending on the dominant industry in the local economy. This result suggests that the advisability of diversification as a policy goal should be conditioned on the specific attributes of the local industry.

Rural specialization as a vestige of the company town archetype provides the strongest argument for industrial diversification as a policy goal. While possible in any industry, the analysis suggests that the pursuit of the monopsony power rationale is more prevalent in the counties specialized in the Paper and Electrical Equipment industries. For these communities, diversification would reduce their vulnerability to shocks and dependence on the dominant industry. Increased competition in the local labor market owing to diversification would also have direct benefits for the workforce. However, the feasibility of industrial diversification as a policy goal is perhaps uncomfortably tied to the political structure of the local economy.

The intermediate case for diversification is found in those counties where manufacturing specialization results from rural necessity. In some cases, specialization may be inevitable because of industries pursuing scale economies in production in small labor markets. The analysis identified that this scenario is most likely with the Food, Textiles, Paper, Chemicals, Primary Metals, and Transportation 
TABLE 6

Marginal Effects at the Means of Three Settlement Size Categories

\begin{tabular}{|c|c|c|c|c|c|c|}
\hline & \multicolumn{2}{|c|}{ Beale 3} & \multicolumn{2}{|c|}{ Beale 5} & \multicolumn{2}{|c|}{ Beale 9} \\
\hline & Marginal Effect & Mean & Marginal Effect & Mean & Marginal Effect & Mean \\
\hline \multicolumn{7}{|l|}{ Food SIC 20} \\
\hline OBS/CORE & 0.00149 & 0.983 & 0.00425 & 1.049 & 0.01113 & 1.089 \\
\hline LOC & 0.00040 & 13.403 & 0.00113 & 10.131 & 0.00296 & 3.974 \\
\hline MON & -0.02642 & 0.268 & -0.07534 & 0.234 & -0.19742 & 0.441 \\
\hline POP & & 93,295 & & 65,367 & & 11,637 \\
\hline \multicolumn{7}{|c|}{ Textiles SIC 22} \\
\hline OBS/CORE & 0.14075 & 0.944 & 0.14424 & 0.513 & 0.21665 & 0.824 \\
\hline LOC & 0.00450 & 27.329 & 0.00461 & 10.701 & 0.00693 & 1.761 \\
\hline MON & -0.49549 & 0.237 & -0.50775 & 0.216 & -0.76266 & 0.441 \\
\hline POP & & 97,679 & & 66,187 & & 14,689 \\
\hline \multicolumn{7}{|c|}{ Apparel SIC 23} \\
\hline OBSS/CORE & 0.00250 & 0.766 & 0.00963 & 0.849 & 0.26905 & 0.924 \\
\hline LOC & 0.00018 & 19.955 & 0.00068 & 9.178 & 0.01896 & 4.031 \\
\hline MON & -0.00109 & 0.283 & -0.00419 & 0.236 & -0.11687 & 0.459 \\
\hline POP & & 86,182 & & 65,949 & & 11,197 \\
\hline \multicolumn{7}{|c|}{ Lumber SIC 24} \\
\hline OBS/CORE & 0.000202 & 0.172 & 0.002303 & 0.216 & 0.353371 & 0.129 \\
\hline LOC & 0.000001 & 37.878 & 0.000008 & 43.543 & 0.001171 & 16.829 \\
\hline MON & 0.000002 & 0.279 & 0.000028 & 0.232 & 0.004257 & 0.491 \\
\hline POP & & 84,708 & & 65,090 & & 10,696 \\
\hline \multicolumn{7}{|c|}{ Furniture SIC 25} \\
\hline OBS/CORE & 0.000030 & 0.394 & 0.000465 & 0.275 & 0.050470 & 0.261 \\
\hline LOC & 0.000001 & 6.808 & 0.000017 & 12.919 & 0.001830 & 2.530 \\
\hline MON & -0.000025 & 0.252 & -0.000389 & 0.222 & -0.042222 & 0.465 \\
\hline POP & & 88,463 & & 65,749 & & 11,900 \\
\hline \multicolumn{7}{|l|}{ Paper SIC 26} \\
\hline OBSS/CORE & 0.00010 & 0.826 & 0.00173 & 1.446 & 0.14086 & 1.167 \\
\hline LOC & 0.00004 & 4.012 & 0.00062 & 4.443 & 0.05062 & 1.113 \\
\hline MON & 0.00180 & 0.242 & 0.03145 & 0.229 & 0.99999 & 0.510 \\
\hline POP & & 94,542 & & 62,722 & & 11,431 \\
\hline \multicolumn{7}{|c|}{ Chemicals SIC 28} \\
\hline OBS/CORE & 0.00751 & 0.932 & 0.01724 & 1.363 & 0.04218 & 0.529 \\
\hline LOC & 0.00026 & 6.189 & 0.00059 & 3.049 & 0.00144 & 1.269 \\
\hline MON & 0.03239 & 0.235 & 0.07435 & 0.234 & 0.18189 & 0.409 \\
\hline POP & & 98,021 & & 66,840 & & 13,002 \\
\hline \multicolumn{7}{|c|}{ Primary Metals SIC 33} \\
\hline OBS/CORE & 0.02422 & 0.546 & 0.02656 & 0.395 & 0.08167 & 0.583 \\
\hline LOC & 0.00208 & 4.184 & 0.00228 & 2.438 & 0.00701 & 1.000 \\
\hline MON & 0.00669 & 0.232 & 0.00734 & 0.224 & 0.02256 & 0.479 \\
\hline POP & & 88,220 & & 67,420 & & 12,165 \\
\hline \multicolumn{7}{|c|}{ Fabricated Metals SIC 34} \\
\hline OBS/CORE & 0.00038 & 0.284 & 0.00128 & 0.303 & 0.06245 & 0.345 \\
\hline LOC & 0.00002 & 20.183 & 0.00006 & 11.167 & 0.00288 & 1.930 \\
\hline MON & 0.00049 & 0.271 & 0.00163 & 0.233 & 0.07958 & 0.437 \\
\hline POP & & 88,116 & & 63,868 & & 11,758 \\
\hline \multicolumn{7}{|c|}{ Electrical Eq. SIC 36} \\
\hline OBS/CORE & 0.00614 & 0.756 & 0.01045 & 0.981 & 0.07396 & 0.432 \\
\hline LOC & 0.00025 & 6.392 & 0.00042 & 3.374 & 0.00300 & 1.206 \\
\hline MON & 0.05077 & 0.253 & 0.08644 & 0.226 & 0.61187 & 0.444 \\
\hline POP & & 98,660 & & 66,042 & & 13,979 \\
\hline \multicolumn{7}{|c|}{ Transportation Eq. SIC 37} \\
\hline OBS/CORE & 0.00761 & 0.238 & 0.02520 & 0.238 & 0.11550 & 0.154 \\
\hline LOC & 0.00027 & 4.609 & 0.00090 & 6.388 & 0.00411 & 1.878 \\
\hline MON & -0.00171 & 0.249 & -0.00566 & 0.235 & -0.02592 & 0.473 \\
\hline POP & & 93,084 & & 65,962 & & 10,715 \\
\hline
\end{tabular}


Equipment industries. For the counties specialized in these industries, diversification of itself will not work at cross-purposes to the rationale of industry specialization. Rather, any technical economies in production may impose substantial "portfolio constraints" on how employment is distributed across industries. Public policies that reduce the volatility of local employment demand (e.g., sheltering profits that are used for skill upgrading during downturns) and increase the flexibility of existing plants to respond to changes in demand may be a more feasible approach than attracting new industries. Real conflicts may emerge, however, in considering the advisability of substantial expansion of an existing plant relative to the attraction of diversified employment.

Finally, the analysis provides evidence for specialization promoting rural possibility through the formation of localization economies in the counties specialized in the Textiles and Furniture industries. The localization rationale for specialization presents a counter to the benefits of diversification. If a critical mass of independent firms is a prerequisite for the competitiveness of local industry, then the goal of diversification would merely dilute the possibility of external economies. The appropriate policy response is made more difficult by the substantial import penetration in those industries identified as most likely to generate external economies. Yet, the folly of trying to pick the most appropriate industrial structure argues against either the purposive concentration or divestment of these industries. Rather, policy in this instance (and in all other contexts where localization benefits are evident) should concentrate on enhancing the already extant localization benefits. Training consortia, specialized machine or business service bureaus, facilitating coproduction relations-among other "real services"are clear and proven means of increasing the competitiveness of local economies that have already begun to discover the advantages of localization (Brusco 1992).

This analysis reveals that industrial specialization in the rural Southeast may result from "necessity," "possibility," or "vestige" depending on the local industrial structure. It is important to note that the rationales for manufacturing specialization identified here are merely suggestive of the causes underlying the observed specialization. It is only through analysis of the outcomes of this specialization in combination with some understanding of the causes that informed policy choices can be made. With a greater understanding of the possible causes provided by this analysis, examination of the outcomes in the specialized counties can better inform the costs and benefits of particular economic structures leading to more reasoned policy prescriptions.

\section{APPENDIX}

The axiomatic origin of the localization measure-referred to below as MHerf for Modified Herfindahl--is to find a measure increasing in the number of firms in a locale and increasing in the dispersion of employment across these firms. A measure that satisfies these two requirements is constructed by dividing the number of firms in a local industry (e.g., 2-digit SIC) by the Herfindahl Con- 
centration index (computed with respect to employment share) for the local industry:

$$
\text { MHerf }_{i}=\frac{\text { Number of Firms }_{i}}{\sum_{n \text { in }}\left(\frac{\text { Establishment Employment }_{n}}{\text { Industry Employment }_{i}}\right)^{2}} .
$$

However, a more intuitive expression for the Herfindahl index is Herf $=1 / \mathrm{N}+\mathrm{N} \sigma^{2}$, where $N$ is the number of firms in industry $i$ and $\sigma^{2}$ is variation in employment shares around the mean employment share. Thus MHerf can also be expressed as:

$$
\text { MHerf }_{i}=\frac{N}{\left(1 /\left(N+N \sigma^{2}\right)\right)}=\frac{N^{2}}{\left(1 /\left(1+N^{2} \sigma^{2}\right)\right)} .
$$

Finally, the limiting values of $\sigma^{2}$ are 0 for equally distributed shares and $1 / N-1 / N^{2}$ as all employment becomes concentrated in one firm. Thus the limiting values for MHerf $=\mathrm{N}$ when employment is concentrated in one firm, and MHerf $=\mathrm{N}^{2}$ when employment is equally distributed.

Heuristically, MHerf $=\mathrm{N}$ can be interpreted as a network flow between a dominant hub firm and its dependent spokes (though this is technically N-1 interactions). At the other end, the measure represents the possibility that any firm interacts with all other firms in the locale (again, this is technically $\mathrm{N}^{*}(\mathrm{~N}-1)$ interactions, not $\mathrm{N}^{2}$ ).

However, the intermediate cases are also instructive and suggest that the measure increases as the local industrial structure approaches the Marshallian district archetype. For example, if the dominant firm has 50 percent of employment then the measure takes on the value $(\mathrm{N}-1)^{*} 4$ (the remaining employment distributed equally across the nondominant firms). Further, if this dominant 50 percent share is split between two firms, then MHerf $=(\mathrm{N}-2) * 8$; split between three firms then, MHerf $=(\mathrm{N}-3)^{*} 12$; split between four firms, then MHerf $=(\mathrm{N}-4)^{*} 16$, etc.

If it is assumed that Marshallian districts are infrequent-rare in the rural case-then one would anticipate that a valid measure would be "peaky" (i.e., high kurtosis). This is confirmed in an examination of descriptive statistics of the measure across the various industries. However, this "peakiness," or the tendency for the measure to explode as the local firm structure comes to resemble the Marshallian archetype, is perhaps best examined with the help of the Lorenz curve. That is, we examine the ranked cumulative share of the value of the measure by the share of ranked nonmetropolitan counties. As an example, our sample contains 246 nonmetropolitan counties with employment in the Furniture industry (SIC 25). However, nearly 10 percent of the total value of the MHerf variable is claimed by the top county (Chickasaw County, MS). The top 5 percent of counties account for roughly 50 percent of the total value of the proxy. In contrast, the lower 75 percent of counties account for less than 20 percent of this value. 


\section{REFERENCES}

Barkley, D.L., and M.S. Henry. "Rural Industrial Development: To Cluster or Not to Cluster?" Review of Agricultural Economics 19 (2) (1997), 308-325.

Becattini, G. "The Marshallian Industrial District as a Socio-Economic Notion." In F. Pyke, G. Becattini, and W. Sengenberger (eds.) Industrial Districts and Inter-Firm Cooperation in Italy. Geneva: International Institute for Labour Studies, 1990.

Boal, W.M. "Testing for Employer Monopsony in Turn-of-the-Century Coal Mining." RAND Journal of Economics 26 (1995), 519-536.

Brown, D., and J. Pheasant. "Sources of Cyclical Instability in Rural Counties." American Journal of Agricultural Economics 69 (1987), 819-827.

Brusco, S. "Small Firms and the Provision of Real Services." In F. Pyke and W.

Sengenberger (eds.) Industrial Districts and Local Economic Regeneration.

Geneva: International Institute for Labour Studies, 1992.

Cook, P.J., and K.L. Mizer. "The Revised ERS County Typology: An Overview."

Rural Development Research Report Number 89. Washington, D.C.: U.S.

Department of Agriculture, 1994.

Eckard, E.W., Jr. "Plant-Level Scale Economies and Industrial Concentration."

Quarterly Review of Economics and Finance 34 (2) (1994), 173-182.

Gilchrist, D.A., and L.V. St. Louis. "Directions for Diversification with an Application to Saskatchewan." Journal of Regional Science 31 (3) (1991), 273-289.

Goldberger, A.S. A Course in Econometrics. Cambridge, MA: Harvard University Press, 1991.

Griffiths, W.E., R.C. Hill, and G.G. Judge. Learning and Practicing Econometrics.

New York: John Wiley \& Sons, Inc., 1993.

Henry, M.S., D.L. Barkley, and Y. Zhang. "Industry Clusters in the TVA Region: Do

They Affect Development of Rural Areas?" TVA Rural Studies Contractor

Report, www.rural.org/competitive/henry98-9.pdf, 1997.

Henry, M., and M. Drabenstott. "A New Micro View of the U.S. Rural Economy."

Federal Reserve Bank of Kansas City Economic Review 81 (2) (1996), 53-70.

Jones, D.W. "Monopsony and Plant Location in a Thunen Land Use Model." Journal of Regional Science 28 (1988), 317-327.

Kilkenny, M. "Transportation Costs, the New Economic Geography, and Rural Development." Growth and Change 29 (1998), 259-280.

Kreahling, K.S., S.M. Smith, and C. Frumento. "A Procedure for Estimating Nondisclosed Employment in the County Business Patterns Data Set."

Pennsylvania State University Department of Agricultural Economics and Rural Sociology Staff Paper Number 299, 1996.

Kristensen, P.H. "Industrial Districts in West Jutland, Denmark." In F. Pyke and W. Sengenberger (eds.) Industrial Districts and Local Economic Regeneration.

Geneva: International Labor Organization, 1992.

Krugman, P.R. Geography and Trade. Cambridge, MA: The MIT Press, 1991. 
Long, J.S. Regression Models for Categorical and Limited Dependent Variables. Thousand Oaks, CA: Sage Publications, 1997.

Marshall, A. Principles of Economics. London: MacMillan, 1920.

Milgrom, P., and J. Roberts. "The Economics of Modern Manufacturing: Technology, Strategy, and Organization." American Economic Review 80 (3) (1990), 511-528.

Piore, M.J. "Work, Labour and Action: Work Experience in a System of Flexible Production." In F. Pyke, G. Becattini, and W. Sengenberger (eds.) Industrial Districts and Inter-Firm Cooperation in Italy. Geneva: International Institute for Labour Studies, 1990.

Piore, M.J., and C.F. Sabel. The Second Industrial Divide: Possibilities for Prosperity. New York: Basic Books, 1984.

Pyke, F., and W. Sengenberger (eds.) Industrial Districts and Local Economic Regeneration. Geneva: International Institute for Labour Studies, 1992.

Romer, P.M. "Increasing Returns and Long-Run Growth." Journal of Political Economy 94 (5) (1986), 1003-1026.

Schmitz, H. "Industrial Districts: Model and Reality in Baden-Württemberg, Germany." In F. Pyke and W. Sengenberger (eds.) Industrial Districts and Local Economic Regeneration. Geneva: International Institute for Labour Studies, 1992

Sforzi, F. "The Quantitative Importance of Marshallian Industrial Districts in the Italian Economy." In F. Pyke, G. Becattini, and W. Sengenberger (eds.) Industrial Districts and Inter-Firm Cooperation in Italy. Geneva: International Institute for Labour Studies, 1990.

Shaffer, R. Community Economics: Economic Structure and Change in Smaller Communities. Ames, IA: Iowa State University Press, 1989.

Smith, S.M., and C.M. Gibson. "Industrial Diversification in Nonmetropolitan Counties and its Effect on Economic Stability." Western Journal of Agricultural Economics 13 (1988), 193-201.

Yeh, C., C. Mai, and Y. Shieh. "Location and Theory of Production Under Monopsony." Papers in Regional Science 75 (1996), 433-440. 
